\title{
Influence of Germination Conditions and Parameters on the Content of Total Phenolic Compounds and Scavenging Activity in Germinated Seeds
}

\author{
*Ilze Bernate, Martins Sabovics, Lolita Tomsone \\ Faculty of Food Technology, Latvia University of Life Sciences and Technologies, Liela iela 2, Latvia
}

\begin{abstract}
Consumers are increasingly consuming sprouted seeds due to their low calories content, nutritional value, as well as beneficial effects on human health. Sprouts contain many bioactive compounds such as minerals, fibre, vitamin C, carotenoids and phenolic compounds. The aim of this study was to determine the effects of darkness, light and time total phenolic content and scavenging activity in alfalfa (Medicago sativa), radish (Raphanus sativus), broccoli (Brassica oleracea) and hemp (Cannabis sativa) seeds during germination. The seeds were washed, soaked in water by ratio of 2:1 (water : seeds) for $12 \pm 1 \mathrm{~h}$ and then germinated in light and dark conditions at a temperature of $22 \pm 2{ }^{\circ} \mathrm{C}$ and a relative humidity of $85 \pm 2 \%$ for different times $(12,24$, 36 and 48 hours) in a climatic chamber ICH110 (Memmert, Germany). The quality changes of germinated seeds are determined by phenol content and scavenging activity. Un-germinated seeds were used as a control. The results of current studies show that after germination the highest increase in total phenols was in radish, broccoli and alfalfa seeds. The scavenging activity (SA) was higher after 48 hours of germination in all seed types compared to un-germinated seeds both in darkness and in light. This study shows that sprouted edible seeds are an excellent source of total phenolic compounds and has a high scavenging activity.
\end{abstract}

Keywords: germination, phenols, antioxidants, seeds, sprouts.

\section{Introduction}

In ancient times, sprouted seeds in the Far East were recognized as healthy food. Because of lifestyle changes and the growing interest in healthy eating around the world in recent years, the consumption of sprouts has increased, especially in the West (Sikin, Zoelner, \& Rizvi, 2013). Therefore, sprouts are popular worldwide for their nutritional and health benefits. Raw agricultural products provide not only the nutrients for the human body needs, but also biologically active compounds that promote health and prevent various types of disease. Germinated seeds are rich in proteins, carbohydrates, fibre and vitamins, especially vitamin $\mathrm{C}$, which is produced during the germination process. Seed germination is an ancient method of processing that has been used in the Far East for many centuries (Taraseviciene et al., 2009). The content of phenolic compounds in sprouts can be influenced by many factors, such as plant species, germination time, and the presence of light (Lee et al., 2014). Antioxidants, including plant polyphenols, can protect the body from free radicals (Chen et al., 2012; Frassinettia el al., 2018). In food processing, several technologies have been developed to reduce the loss of phenolic compounds in products during processing, as well as to increase their content. The germination process could increase the quantity and quality of bioactive compounds, the nutritional value of the products. During soaking, first of all, water enters in the tissues, activating inactive tissues, but also activating metabolism. However, soaking is mainly a physical process that removes dirt and microorganisms from the seeds. Germination activates endogenous cereal enzymes, when proteins and carbohydrates are hydrolysed into smaller molecules as mono-, disaccharides, dextrin's, peptides, free amino acids, and additionally new bioactive compounds are synthetized (Wu et al., 2013). Therefore, the content of bioactive compounds in germinated seeds can be affected by various conditions, such as germination time, light, etc.

\footnotetext{
* Corresponding Author's email:

ilze.bernate@inbox.lv
} 
There are facts that plants of the cruciferous family, such as spinach (Spinacia oleracea), Brussels sprouts (Brassica oleracea var. gemmifera), cauliflowers (Brassica oleracea var. botrytis), broccoli (Brassica oleracea), oilseed rape (Brassica napus), and radishes (Raphanus sativus) contain significant amounts of biologically active compounds (Martinez-Villaluenga et al.,2008).

Broccoli (Brassica oleracea) is a plant with a very rich source of nutritional ingredients and biologically active compounds such as minerals, vitamin C, fibre, secondary metabolites such as phenolic compounds (PC) and glycosinolates (GLS) (Baenas, Moreno, \& Garcia-Viguera, 2012; Mahn \& Perezs, 2016; Ferreira et al., 2018). In recent years, broccoli seeds and seedlings have attracted much research interest due to their much higher levels of glucoraphanin and endogenous merozinase than mature plants (PérezBalibrea, et al., 2011; Guo et al., 2014). The research of Herr and Büchler (2010) has also shown that bioactive substances can reduce the risk of many diseases, because they have a beneficial effect on human health.

Radish (Raphanus sativus) belongs to cruciferous family. Although radishes are traditionally consumed as root vegetables, leaves and sprouts are edible, too. Sprouts have become popular because of their low fat and richness in phytochemicals (MartinezVillaluenga et al., 2010). Edible seeds and seedlings are a good source of trace elements, vitamins and antioxidants such as phenolic acids and flavonoids. (Pasko et al., 2009).

Alfalfa (Medicago sativa) is a crop of the Leguminosae family and one of the most economically valuable crops in the world (Graham \& Vance, 2003). Alfalfa is considered a valuable crop due to its high nutritional value and being a valuable fodder crop. Humans can safely use their edible seeds and sprouts as a source of protein (EFSA, 2009). Giuberti et al. (2018) found in their study that the total phenol content (TPC) of alfalfa seeds is equivalent to that of TPC grape (Vitis vinifera) seed, green tea (Camellia sinensis) and rosemary (Rosmarinus officinalis) extracts.

Hemp (Cannabis sativa) belongs to the Cannabinaceae family. Hemp has been known to play a historically important role in the production of food, fibre and medicines. Currently, products derived from hemp seeds (oil, protein powder, meal) are gaining popularity in human consumption as a great source of nutrients that contain all the fatty acids and essential amino acids (Werz et al., 2014; Andre, Hausman, \& Guerriero, 2016). Cannabis seeds are rich in minerals (phosphorus, potassium, sodium, magnesium, sulphur, calcium, iron and zinc). They contain insoluble fibre, vitamin E, as well as up to $35 \%$ lipids, of which more than $80 \%$ are polyunsaturated fatty acids (Callaway, 2004; Rodriguez-Leyva \& Pierce, 2010).

The aim of this study was to determine the effect of darkness, light and time on total phenolic content and scavenging activity in alfalfa (Medicago sativa), radish (Raphanus sativus), broccoli (Brassica oleracea) and hemp (Cannabis sativa) seeds during germination.

\section{Materials and Methods}

Plant materials. The seeds were purchased in the local market. Broccoli expiration date November 2021, Lot: $62 / 14$ and radish seeds expiration date July 2021, Lot: 275/A, originated in Italy in 2019, hemp and alfalfa seeds were grown in Latvia in 2019. The research was carried out in the scientific laboratories of the Faculty of Food Technology, Latvia University of Life Sciences and Technologies.

Seeds germination. The seeds were soaked, first washed in potable water until the drained water was visually clear. The pure seeds were soaked in drinking water in a ratio of 2:1 (water:seeds). The soaking was done in a plastic bowl for $12 \mathrm{~h}$ in the dark time of the day at a temperature of $+22 \pm 2{ }^{\circ} \mathrm{C}$. After $12 \mathrm{~h}$ the seeds were rinsed in drinking water until the rinsing water was visually clear. Rinsing is the main physical treatment process that separates dirt and microorganisms from seeds. The clean soaked seeds were divide into two parts (I and II). Part I was use for sprouting in light (800 lux), but part II - in darkness (0 lux). Dark and light conditions were provided in a climatic chamber device ICH110 (Memmert, Germany)). Each part was divided into four equal parts before germination. They were germinated for a period of time $12,24,36$ or $48 \mathrm{~h}$. After this time, four parts of seeds were dried at $55 \pm 3{ }^{\circ} \mathrm{C}$, the air flow rate was $1.2 \pm 0.1 \mathrm{~ms}^{-1}$ for $12 \mathrm{~h}$. For drying a convective dryer Universal Oven UF55 (Memmert $\mathrm{GmbH}+\mathrm{Co}$. $\mathrm{KG}$ was used (Germany), then they were grounded in an electric coffee grinder (manufacturer "STRAUME" (Latvia) article 1C30243598). Extracts were prepared from the grounded seed samples. As a control samples un-soaked and un-germinated seeds were tested.

Extraction and determination of total phenolic compounds and antioxidant activity

Extraction. Extracts to measure total phenolic content (TPC) and scavenging activity (SA) were prepared. The extraction process was performed as described by Kruma et al. (2016).

Total phenolic content (TPC) in seed extracts was determined by the Singleton method (Singleton, Orthofer, \& Lamuela-Raventos, 1999). $0.5 \mathrm{ml}$ of the extract was taken to be analysed and $2.5 \mathrm{ml}$ of Folin-Ciocalteu reagent (diluted 1:10 with distilled water) was added. It was held for 5 minutes, and then 
$2.0 \mathrm{ml}$ of $7.5 \% \mathrm{Na}_{2} \mathrm{CO}_{3}$ was added. It was mixed and left for 30 minutes. The absorbance was read at $\lambda=765 \mathrm{~nm}$ using a JENWAY 6300 spectrophotometer (Baroworld Scientifild Ltd, UK). TPC of the test samples were expressed in milligrams of gallic acid equivalents (GAE) per $100 \mathrm{~g}$ dry weight of the sample (mg GAE $100 \mathrm{~g}^{-1}$ dry weight).

A stable 2.2-diphenyl-1-picrylhydrazyl (DPPH) radical reagent ( $\mathrm{Yu}$, et al., 2003) was used to determine the radical scavenging activity. Freshly prepared $\mathrm{DPPH}^{\circ}$ reagent $\left(0.004 \mathrm{~g} \mathrm{DPPH}^{\circ}\right.$ per $100 \mathrm{ml}$ ethanol) was used. $0.5 \mathrm{ml}$ of the extract for analyses was taken, and then $3.5 \mathrm{ml}$ of $\mathrm{DPPH}^{*}$ reagent was added. It was mixed and left for 30 minutes. The absorbance was read at $\lambda=517 \mathrm{~nm}$ using a JENWAY 6300 spectrophotometer. The scavenging activity was expressed as Trolox equivalents (TE) $100 \mathrm{~g}^{-1} \mathrm{DW}$ of plant material. (Baroworld Scientifild Ltd., UK).

Moisture content. Moisture content of seeds and sprouts samples was determined according to the standard of LVS EN ISO 712:2010. The moisture content of the seeds and sprouts was determined by air-oven method by drying $5.00 \pm 0.05 \mathrm{~g}$ of sample in Memmert oven (GmbH Memmert, Germany) for 1 hour at $110 \pm 5^{\circ} \mathrm{C}$. Afterwards the moisture samples were cooled in a desiccator. All analyses were performed in triplicate.

Statistical analysis. Microsoft Excel 2016 software and SPSS 17.00 were used for mathematical data processing. Differences between samples with significance (that $\alpha=0.05$ with $95 \%$ confidence) were determined using ANOVA, Tukey tests. Pearson test was use for correlation analyses between TPC and $\mathrm{DPPH}^{\circ}$.

\section{Results and Discussion}

Total phenolic content (TPC)

Analysing control samples, the results showed significantly $(\mathrm{P}<0.05)$ different TPC content between seed types (Figure 1). Un-germinated alfalfa seeds has a higher TPC content $\left(288.37 \pm 25.11 \mathrm{mg} \mathrm{GAE} 100 \mathrm{~g}^{-1}\right.$ DW) comparing with other control seed samples. Lower content of TPC in control samples were detected in hemp seeds $\left(46.71 \pm 2.11 \mathrm{mg}\right.$ GAE $100 \mathrm{~g}^{-1}$ DW). Germinated alfalfa seeds after 12, 24, 36 hours in darkness and in light did not reach the content of alfalfa control sample but by germinating these seeds $48 \mathrm{~h}$ in the dark and light, it is possible to increase the content of TPC. After $48 \mathrm{~h}$ TPC content reached to $343,12 \pm 52.68 \mathrm{mg}$ GAE $100 \mathrm{~g}^{-1} \mathrm{DW}$ and $337.7 \pm$ $51.90 \mathrm{mg}$ GAE $100 \mathrm{~g}^{-1}$, respectively. Broccoli is a rich source of phytochemicals (glycols and phenol compounds) as well as trace elements vitamins and minerals (Perez-Balibrea, et al., 2008). The analysed broccoli seed also had a high TPC content $\left(208.00 \pm 19.30 \mathrm{mg}\right.$ GAE $\left.100 \mathrm{~g}^{-1} \mathrm{DW}\right)$. This is consistent with previously reported data from a similar study (Moreno et al., 2006). Slightly less TPC was detected for the other seed of the cruciferous plant radishes $\left(172.47 \pm 19.65 \mathrm{mg}\right.$ GAE $\left.100 \mathrm{~g}^{-1} \mathrm{DW}\right)$. Hemp (Cannabis sativa) seed is a great source of nutrients. Both traditional Chinese medicine and clinical trials have found evidence of health-enhancing properties of hemp seed. This is mainly due to the high lipid content and protein, which is a source of important amino acids and easily digestible proteins (Callaway, 2004). However, there are no studies in scientific literature on the content of phenol compounds in hemp seeds; therefore, it is not possible to compare data with other scientific papers. Despite the fact that all types of hemp seed had the least TPC (34.88 \pm

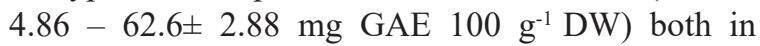
darkness and in light. Studied data shows that using germination process, it is possible to increase TPC content as $34 \%$ compared to the control.

Sprouting process significantly $(\mathrm{P}<0.05)$ affects total phenol content (TPC) in the analysed seeds (Figure 1). In general, the tested sprouted seed can be ranked according to TPC as follows (starting with the highest TPC): in radishes $>$ broccoli $>$ alfalfa $>$ hemp both in darkness and in light. The highest TPC was found in sprouted radish seeds after $36 \mathrm{~h}$ in the dark $439.72 \pm 39.28 \mathrm{mg}$ GAE $100 \mathrm{~g}-1 \mathrm{DW}$ and in the light $449.20 \pm 66.10 \mathrm{mg}$ GAE $100 \mathrm{~g}-1 \mathrm{DW}$. During the germination process, it increased by 2.66 times compared to the control (Figure 1). This was the greatest benefit of healing among the analysed seeds. A $72 \%$ increase in TPC was observed in sprouted broccoli compared to control and in these seeds TPC hesitate $12 \mathrm{~h}$ in the dark from $171.90 \pm 10.66 \mathrm{mg}$ GAE $100 \mathrm{~g}^{-1} \mathrm{DW}$ to $358.00 \pm 39.29 \mathrm{mg}$ GAE $100 \mathrm{~g}^{-1} \mathrm{DW}$ after $24 \mathrm{~h}$ in the dark.

In germinated alfalfa seeds, the TPC hesitate from $135.44 \pm 33.65 \mathrm{mg}$ GAE $100 \mathrm{~g}^{-1} \mathrm{DW}$ after $12 \mathrm{~h}$ in the light to $343.12 \pm 52.48 \mathrm{mg}$ GAE $100 \mathrm{~g}^{-1} \mathrm{DW}$ after $48 \mathrm{~h}$ in the dark, where the sprouting result succeeded in increasing TPC by only 19\% compared to control.

When analysing seeds germinated in the dark, a higher TPC was obtained than in the light-sprouted seed, with the exception of radish seed.

However, the results of scientific literature have shown that a higher TPC was achieved by germinating seeds in the presence of light. (Perez-Balibrea, Moreno, \& Garcia-Viguera, 2008).

At the same time, the light-sprouted seed was generally more TPC than in the control samples. Higher phenol content was observed in the darkness during germination, possibly due to the mobilization of carbohydrates from cotyledons targeting the high nutrient levels of growing sprouts (Randhir \& Shetty, 2005). 
A

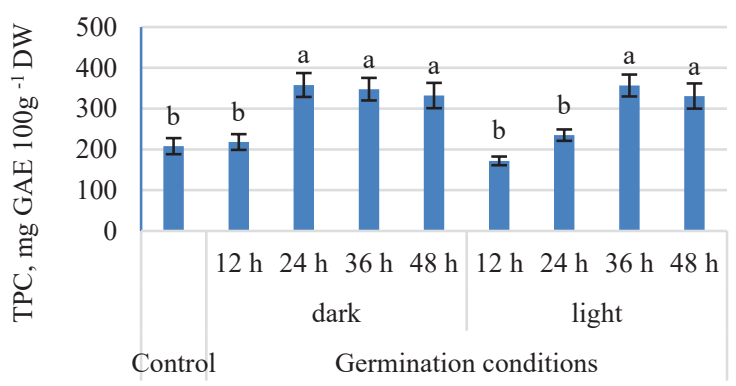

B

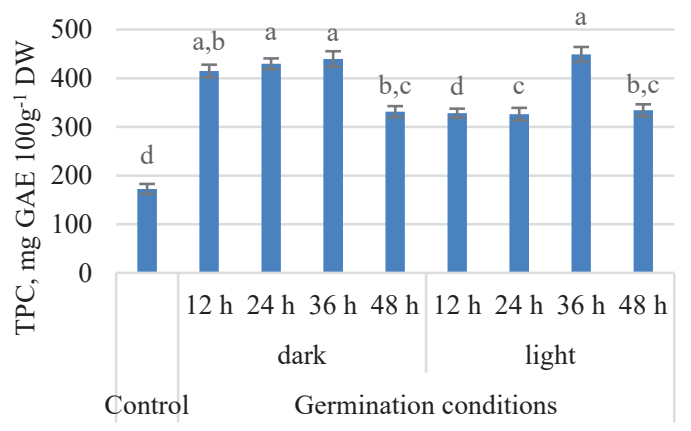

C

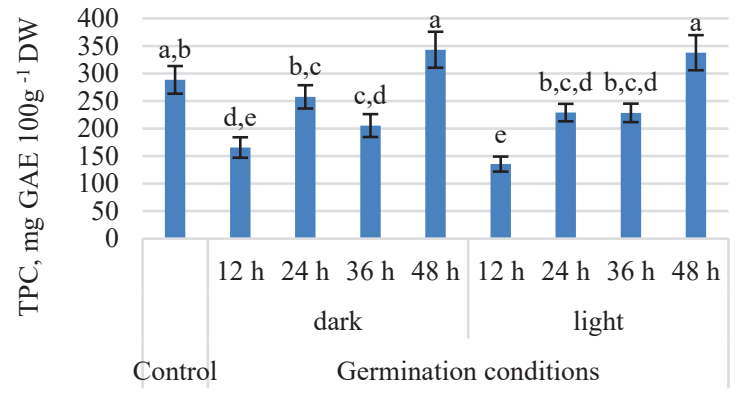

D

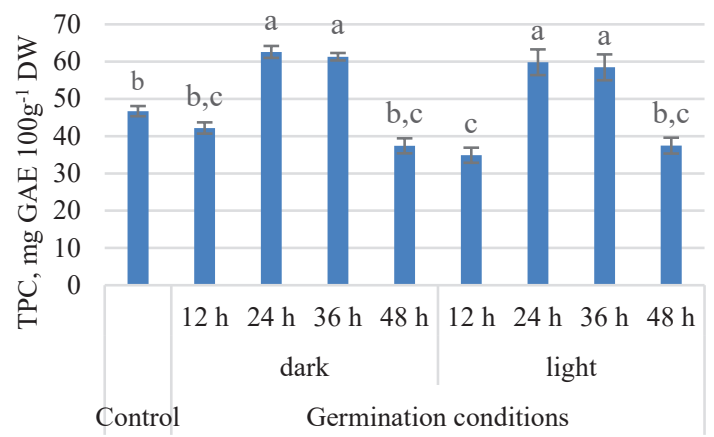

Figure 1. Changes of TPC during germination process in broccoli (A), radish (B), alfalfa (C) and hemp (D).

Note: the values marked with different letters for each seed type represent significant differences between values $(P<0.05)$.

Germination time also significantly affects (P $<0.05$ ) the amount of TPC and changes in sprouts. Overall, data shows that after $12 \mathrm{~h}$ germination TPC increased in broccoli and radish seeds compared to un-germinated seeds, except alfalfa and hemp seeds germinated in the dark. This can be explained by soaking process. Although prolonging the germination time, there is a tendency in an increase in TPC content; however, in general, the optimal germination time is $36 \mathrm{~h}$. However, as far as $48 \mathrm{~h}$ is concerned, the TPC content was reduced compared to $36 \mathrm{~h}$ germinated seeds. However, considering each seed type separately, the optimal germination time for each seed type can be optimized. For example, alfalfa seeds had the highest TPC after $48 \mathrm{~h}$ germination in the dark, but hemp and broccoli seeds had it after $24 \mathrm{~h}$ in the dark. This indicates the individual chemical composition of each plant and the different biochemical processes in them. Scavenging activity (SA)

The highest SA was found in broccoli seeds (31.96 $\pm 1.54 \mathrm{mmol}$ TE $\left.100 \mathrm{~g}^{-1} \mathrm{DW}\right)$. The analysed radish seeds also had a high scavenging activity (31.48 $\pm 0.91 \mathrm{mmol}$ TE $\left.100 \mathrm{~g}^{-1} \mathrm{DW}\right)$, which is in accordance with previously reported data (Moreno et al., 2006). Slightly lower scavenging activity was found in alfalfa seeds $\left(23.65 \pm 1.57 \mathrm{mmol}\right.$ TE $100 \mathrm{~g}^{-1}$ DW). The lowest content of scavenging activity was in un-germinated hemp seeds $(3.94 \pm 0.33 \mathrm{mmol} \mathrm{TE}$ $\left.100 \mathrm{~g}^{-1} \mathrm{DW}\right)$.

The germination process significantly affects $(\mathrm{P}$ $<0.05)$ the scavenging activity of the analysed seeds (Figure 2.). In general, the tested sprouted seeds can be ranked according to scavenging activity as follows (starting with the highest scavenging activity): in broccoli $>$ radishes $>$ alfalfa $>$ hemp.

The largest scavenging activity was found in germinated broccoli seeds, where it ranged from $31.96 \pm 1.54 \mathrm{mmol}$ TE $100 \mathrm{~g} \mathrm{~g}^{-1} \mathrm{DW}$ in the light to $30.11 \pm 0.68 \mathrm{mmol}$ TE $100 \mathrm{~g} \mathrm{~g}^{-1} \mathrm{DW}$ after $24 \mathrm{~h}$ in the dark. This was the highest content of scavenging activity among the analysed seeds. In the germination process, it increased by 5 times compared to control in germinated broccoli. In the broccoli seeds it fluctuated after $12 \mathrm{~h}$ both in darkness and in the light from $6.2 \pm 0.19 \mathrm{mmol}$ TE $100 \mathrm{~g}^{-1} \mathrm{DW}$ to $31.96 \pm 1.54 \mathrm{mmol}$ TE $100 \mathrm{~g}^{-1} \mathrm{DW}$ after $24 \mathrm{~h}$ in the light. This is in line with the data from scientific literature that germinated Cruciferous seeds have higher scavenging activity compared to un-germinated (Zielinski et al., 2007; Taraseviciene et al., 2019). Despite the increase 


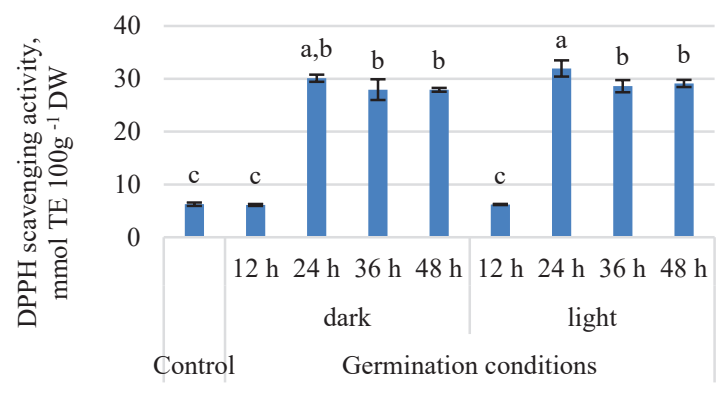

B

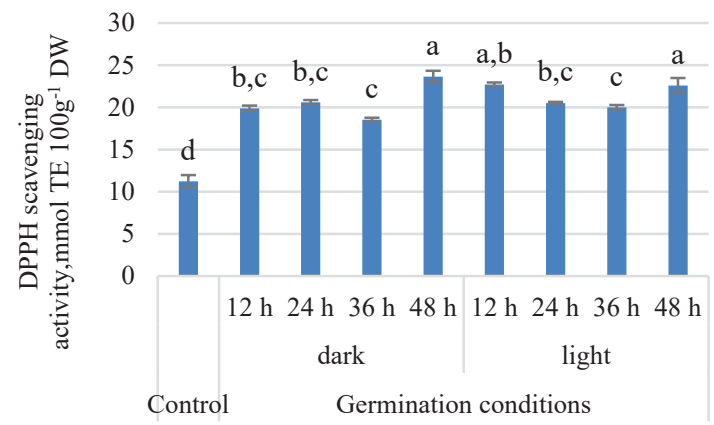

C

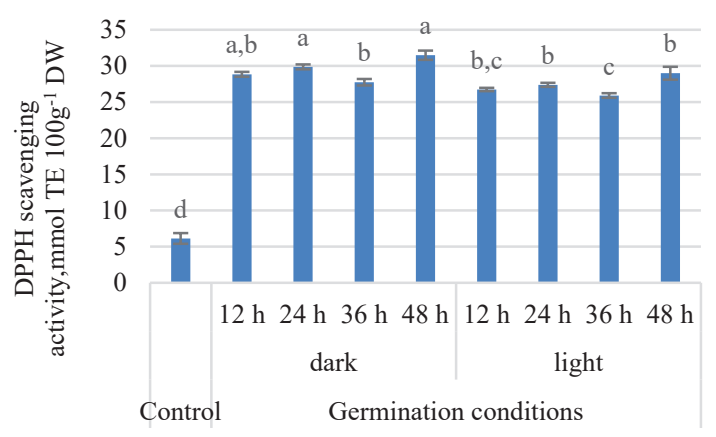

D

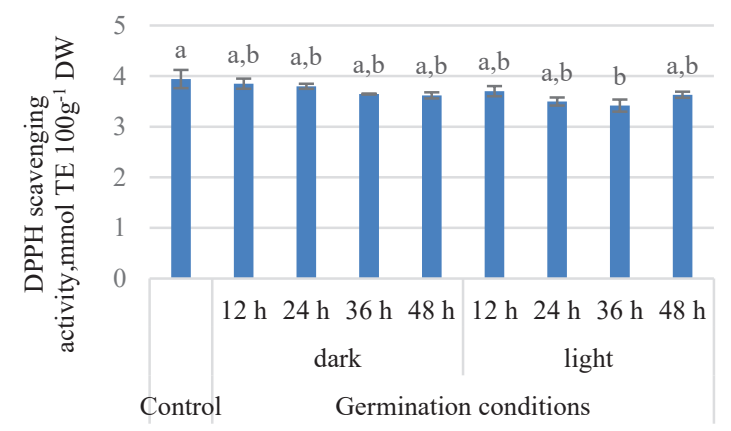

Figure 2. Dynamics of DPPH scavenging activity during germination process in broccoli (A), radish (B), alfalfa (C) and hemp (D).

Note: the values marked with different letters for each seed type represent significant differences between values $(P<0.05)$.

in TPC during germination process, hemp seeds scavenging activity decreased. The reduction was to $3 \%$ for hemp seeds after $36 \mathrm{~h}$ in the dark compared to control samples.

Vale et al. (2015) found that light has a pronounced effect on the formation of secondary metabolites in plants.

In the scientific literature, studies show that the beneficial and adverse effects of light on the content of various compounds in plant products have been demonstrated, thereby altering their nutritional value (Lee et al., 2014, 2016; Kwack et al., 2015; Liu et al., 2016).

Seeds analysed by germination in light and dark scavenging activity significantly increase at similar positions within the error limits in broccoli seeds from $24 \mathrm{~h}-48 \mathrm{~h}$ compared to the control sample and germination after $12 \mathrm{~h}$. In turn, the scavenging activity of radish seeds increases already after $12 \mathrm{~h}$ germination in comparison with the control sample. It is similar to the results of other researchers that the germination of sprouted broccoli and radishes is higher than that of un-germinated seeds (Zielinski et al., 2007; Taraseviciene et al., 2019). Scavenging activity was reduced significantly in the hemp seeds after 36 hours germination in the light compared to the control sample, which may be related to freely soluble phenols that have not decomposed at this stage of the polymerization process (Perez-Balibrea, Moreno, \& Garcia-Viguera, 2008).

Germination time also had a significant $(\mathrm{P}<0.05)$ effect on scavenging activity in the analysed seeds.

The seeds contain many different phenolic compounds that have antioxidant properties. Thanks to this potential, a large range of phytochemical products have a positive effect on overall health (Masisi, Beta, \& Moghadasian, 2016).

Table 1 summarizes Pearson's correlation coefficients between the TPC and SA separately for each seed type, as well as the total correlation, taking into account all the obtained results and the analysed influencing factors.

In general, for all analysed seeds Pearson correlation coefficients between the content of phenolic compounds and scavenging activity were high $r=0.72$. A strong positive correlation between total phenol content and scavenging activity was found for broccoli $(r=0.79)$ and hemp $(r=0.68)$. This suggests that as the TPC in these seeds increases, so does the scavenging activity. Evidence has been found 
Correlation between TPC, DPPH radical scavenging activity in seeds

\begin{tabular}{|l|c|c|c|c|c|c|}
\hline \multirow{2}{*}{ Seeds } & \multicolumn{7}{|c|}{ Pearson's correlation coefficient } \\
\cline { 2 - 7 } & TPC/DPPH & $\begin{array}{c}\text { TPC/tumsa_ } \\
\text { gaisma }\end{array}$ & $\begin{array}{c}\text { DPPH/tumsa_ } \\
\text { gaisma }\end{array}$ & TPC/time & DPPH/laiks & $\begin{array}{c}\text { laiks/tumsa_- } \\
\text { gaisma }\end{array}$ \\
\hline Broccoli & $0.79^{* *}$ & 0.08 & 0.38 & $0.76^{* *}$ & $0.79^{* *}$ & $0.42^{* *}$ \\
\hline Radish & -0.06 & 0.13 & $0.63^{* *}$ & $0.49^{* *}$ & 0.15 & 0.42 \\
\hline Alfalfa & $0.40^{*}$ & -0.21 & $-0.60^{* *}$ & $0.52^{* *}$ & $-0.48^{* *}$ & $0.42^{*}$ \\
\hline Hemp & $0.68^{* *}$ & 0.15 & -0.03 & -0.21 & -0.36 & $0.42^{*}$ \\
\hline All seeds & $0.72^{* *}$ & 0.01 & 0.17 & $0.26^{* *}$ & 0.15 & $0.42^{* *}$ \\
\hline
\end{tabular}

TPC/DPPH - correlation between total phenolic content and DPPH radical scavenging activity;

TPC/tumsa_gaisma - correlation between total phenolic content and tumsas/gaismas režīmu;

DPPH/tumsa_gaisma - correlation between DPPH radical scavenging activity and tumsas/gaismas režīmu;

TPC/time - correlation between total phenolic content and germination time;

DPPH/time - correlation between DPPH radical scavenging activity and germination time;

time/tumsa_gaisma - correlation between germination time and tumsas/gaismas režīmu;

* correlation is significant at $\mathrm{p}<0.05$;

** correlation is significant at $\mathrm{p}<0.01$.

for a strong correlation between the TPC and SA in different cereals (Chen et al., 2012).

Light also has a strong positive effect on the antioxidant activity of radish seeds $(r=0.63)$, but quite the opposite - a negative effect on alfalfa seeds $(\mathrm{r}=0.60)$. At the same time, broccoli has a strong positive correlation between germination time and $\mathrm{TPC}(\mathrm{r}=0.76)$ and SA $(\mathrm{r}=0.79)$.

\section{Conclusions}

Germination of the specific species, germination time, as well as conditions: the light and dark regime affects the total content of phenolic compounds in the germinated seeds. High levels of total phenolic compounds were found in radish, broccoli and alfalfa seeds; therefore, the germination process increases total phenol compounds in seeds. The presence of phenolic compounds in broccoli, alfalfa and radish seeds were increased in the dark, while darkness and light do not significantly affect the scavenging activity in all seeds during germination. The study show that the higher biologically active compounds content increase can be done by germination in the dark.

\section{References}

Andre, C.M., Hausman, J.F., \& Guerriero, G. (2016). Cannabis sativa: The plant of the thousand and one molecules. Frontiers in Plant Science, 7, 1-17. DOI: 10.3389/fpls.2016.00019.

Baenas, N., Moreno, D.A., \& Garcia-Viguera, C., (2012). Selecting sprouts of Brassicaceae for optimum phytochemical composition. J. Agric. Food Chemistry, 60 (45), 11409-11420.
Callaway, J.C. (2004). Hemp seed as a nutritional resource: An overview. Euphytica. 140(1), 6572. DOI: 10.1007/s10681-004-4811-6.

Chen, T., He, J., Zhang, J., Li, X., Zhang, H., Hao, J., \& Li, L. (2012). The isolation and identification of two compounds with predominant radical scavenging activity in hemp seed (seed of Cannabis sativa L.). Food Chemistry, 134(2). 1030-1037. DOI: 10.1016/j. foodchem.2012.03.009.

EFSA (2009). European Food Safety Authority, Scientific opinion on the safety of "Alfalfa protein concentrate" as food. Scientific opinion of the panel on dietetic products, nutrition and allergies (NDA). Question number EFSA-Q-2008-031. The EFSA Journal, 997, 1-19.

Ferreira, S.S., Passos, C.P., Cardoso, S.M., Wessel, D.F., \& Coimbra, M.A. (2018). Microwave assisted dehydration of broccoli by-products and simultaneous extraction of bioactive compounds. Food Chemistry, 246, 386-393.

Frassinettia, S., Moccia, E., Caltavuturoa, L., Gabriele, M., Longo, V., Bellania, L., Giorgic, G., \& Giorgettia, L. (2018). Nutraceutical potential of hemp (Cannabis sativa L.) seeds and sprouts. Food Chemistry. 262, 56-66. DOI: 10.1016/j. foodchem.2018.04.078

Giuberti, G., Rocchetti, G., Sigolo, S., Fortunati, P., Lucini, L., \& Gallo, A. (2018). Exploitation of alfalfa seed (Medicago sativa L.) flour into gluten-free rice cookies: Nutritional, antioxidant and quality characteristics. Food Chemistry. 239, 679-687. DOI: 10.1016/j.foodchem.2017.07.004. 
Graham, P.H., \& Vance, C.P. (2003). Legumes: Importance and constraints to greater use. Plant Physiology, 131, 872-877.

Guo, L.P., Yang, R.Q., Wang, Z.Y., Guo, Q.H., \& Gu, Z.X. (2014). Glucoraphanin, sulforaphane and myrosinase activity in germinating broccoli sprouts as affected by growth temperature and plant organs. Journal of Functional Foods, 9, 70-77.

Herr, I., \& Büchler, M.W. (2010). Dietary constituents of broccoli and other cruciferous vegetables: implications for prevention and therapy of cancer. Cancer Treat. Rev. 36, 377-383.

Kruma, Z., Tomsone, L., Kince, T., Galoburda, R., Senhofa, S., Sabovics, M., E. Straumite., \& Sturite, I. (2016). Effects of germination on total phenolic compounds and radical scavenging activity in hull-less spring cereals and triticale. Agronomy Research, 14(Speciallssue 2), 13721383.

Kwack, Y., Kim, K.K., Hwang, H., \& Chun, C. (2015). Growth and quality of sprouts of six vegetables cultivated under different light intensity and quality. Horticulture, Environment, and Biotechnology, 56(4), 437-443.

Lee, S.W., Seo, J.M., Lee, M.K., Chun, J.H., Antonisamy, P., Arasu, M.V., \& Kim, S.J. (2014). Influence of different LED lamps on the production of phenolic compounds in common and Tartary buckwheat sprouts. Industrial Crops and Products, 54, 320-326.

Liu, H.K., Chen, Y.Y., Hu, T.T., Zhang, S.J., Zhang, Y.H., Zhao, T.Y., \& Kang, Y.F. (2016). The influence of light-emitting diodes on the phenolic compounds and antioxidant activities in pea sprouts. Journal of Functional Foods, 25, 459-465.

Mahn, A., \& Perez, C. (2016). Optimization of an incubation step to maximize sulfor- aphane content in pre-processed broccoli. Journal of Food Science and Technology, 53(11), 41104115.

Martínez-Villaluenga, C., Frías, J., Gulewicz, P., Gulewicz, K., \& Vidal-Valverde, C. (2008). Food safety evaluation of broccoli and radish sprouts. Food and Chemical Toxicology, 46(5), 1635 1644. DOI:10.1016/j.fct.2008.01.004

Martinez-Villaluenga, C., Penas, E., Ciska, E., Piskula, M.K., Kozlowska, H., VidalValverde, C., \& Frias, J. (2010). Time dependence of bioactive compounds and antioxidant capacity during germination of different cultivars of broccoli and radish seeds. Food Chemistry. 120, 710-716. DOI: 10.1016/j.foodchem.2009.10.067.

Masisi, K., Beta, T., \& Moghadasian, M.H. (2016). Antioxidant properties of diverse cereal grains:
Areview on in vitro and in vivo studies. Food Chemistry, 196, 90-97.

Moreno, D.A., Carvajal, M., L'opez-Berenguer, C., \& Garcia-Viguera, C. (2006). Chemical and biological characterisation of nutraceutical compounds of broccoli. Pharmaceut Biomed, 41, 1508-1522.

Pasko, P., Barton, H., Zagrodzki, P., Gorinstein, S., Folta, M., \& Zachwieja, Z. (2009). Anthocyanins, total polyphenols and antioxidant activity in amaranth and quinoa seeds and sprouts during their growth. Food Chemistry. 115, 994-998. DOI: 10.1016/j.foodchem.2009.01.037.

Perez-Balibrea, S., Moreno, D.A., \& Garcia-Viguera, C. (2008). Influence of light on health-promoting phytochemicals of broccoli sprouts. Journal of the Science of Food and Agriculture, 88, 904910.

Pérez-Balibrea, S., Moreno, D. A., \& GarcíaViguera, C. (2011). Genotypic effects on the phytochemical quality of seeds and sprouts from commercial broccoli cultivars. Food Chemistry, 125, 348-354.

Randhir, R., \& Shetty, K. (2005). Developmental stimulation of total phenolics and related antioxidant activity in light- and dark-germinated corn by natural elicitors process Biochemistry, Vol. 40 (5), 1721-1732.

Rodriguez-Leyva, D., \& Pierce, G.N., (2010). The cardiac and haemostatic effects of dietary hempseed. Nutrition \& Metabolism, 7, 32-40.

Sikin, A.M., Zoellner, C., \& Rizvi, S.S. (2013). Current intervention strategies for the microbial safety of sprouts. Journal of Food Protection, 76(12), 2099-2123. DOI: 10.4315/0362-028X. JFP-12-437.

Singleton, V.L., Orthofer, R., \& Lamuela-Raventos, R.M. (1999). Analysis of total phenols and other oxidation substrates and antioxidants by means of Folin-Ciocalteu reagent. Methods in Enzymology, 299, 152-178. DOI: 10.1016/ S0076-6879(99)99017-1.

Taraseviciene, Z., Danilcenko, H., Jariene, E., Paulauskiene, A., \& Gajewski, M. (2009). Changes in some chemical components during germination of broccoli seeds. Notulae Botanicae Horti Agrobotanici Cluj-Napoca 37(2), 173-176. DOI: $10.15835 /$ nbha3723164.

Taraseviciene, Z., Virsile, A., Danilcenko, H., Duchovskis, P., Paulauskiene, A., \& Gajewski, M. (2019). Effects of germination time on the antioxidant properties of edible seeds. CYTA Journal of Food, 17(1), 447-454.

Vale, A.P., Santos, J., Brito, N.V., Peixoto, V., Carvalho, R., Rosa, E., \& Oliveira, M.B.P. (2015). 
Light influence in the nutritional composition of Brassica oleracea sprouts. Food Chemistry, 178, 292-300.

Werz, O., Seerges, J., Shaible, A. M., Weinigel, C., Barz, D., Koeberle, A., Allegrone, G., Pollastro, F., Zampieri, L., Grassi, G., \& Appendino, G. (2014). Cannaflavins from hemp sprouts, a novel cannabinoid-free hemp food pro- duct, target microsomal prostaglandin E2 synthase-1 and 5-lypoxygenase. Pharma Nutrition, 2(3), 53-60. DOI: 10.1016/j.phanu.2014.05.001.

Wu F., Yang N., Touré A., Jin Z., Xu X. (2013) Germinated brown rice and its role in human health. Critical Reviews in Food Science and Nutrition, Vol. 53(5). p. 451-463.

Zielinski, H., Piskuła, M.K., Michalska, A., \& Kozłowska, H., (2007). Antioxidant capacity and its components of cruciferous sprouts. Polish Journal of Food and Nutrition Science, 57(3), 315-322.

Yu, L., Haley, S., Perret, J., Harris, M., Wilson, J. \& Haley, S. (2003). Antioxidant properties of bran extracts from Akron wheat grown at different locations. J. Agric. Food Chemistry,51, 15661570. 